\title{
Different Hemodynamic (24-H Ambulatory Blood Pressure Monitoring) and Renin-Inhibiting Effect of a 1-Week Treatment with Enalapril and Lisinopril
}

\author{
G. COCCO, M.D. (F.E.S.C.), J. HARI, PH.D.
}

Rheinfelden, Switzerland

Summary: Ambulatory blood pressure and heart rate monitoring were used for comparing the antihypertensive effect of a 1-week treatment with enalapril and lisinopril 10 mg once daily (double-blind crossover placebo-controlled study). Twelve outpatients with mild to moderate hypertension were treated. Both drugs had a significant and identical hypotensive effect. Neither drug affected the diurnal rhythm of blood pressure or heart rate. Therefore the two drugs are equipotent antihypertensive agents. Both drugs inhibited ACE activity to a highly significant extent, but in this regard lisinopril was more effective than enalapril. However, lisinopril's greater ACE inhibition was not accompanied by a greater hypotensive effect. The clinical value of this difference is not yet established.

Key words: ACE inhibitors, enalapril, lisinopril, 24-h ambulatory blood pressure monitoring

\section{Introduction}

Enalapril, the prodrug of the angiotensin-converting enzyme (ACE) inhibitor enalaprilat, ${ }^{1}$ is used in the treatment of hypertension. Lisinopril is the lysine analog of enalaprilat ${ }^{2}$ and is also an ACE inhibitor. ${ }^{3}$ Unlike enalapril,

Address for reprints:

G. Cocco, M.D.

P.O. Box 214

CH-4103 Rheinfelden

Switzerland

Received: February 14, 1991

Accepted with revision: June 5, 1991 lisinopril is directly active. ${ }^{4}$ There is also evidence to suggest that lisinopril produces more prolonged inhibition of plasma $\mathrm{ACE}^{5}$ and has a longer-lasting antihypertensive effect than enalapril. ${ }^{6}$ The antihypertensive effect of single doses of enalapril and lisinopril is known, ${ }^{7}$ but it is conceivable that the response might be different after several days of active therapy. To our knowledge, direct comparative data from treatment more than one day were unavailable. On the other hand, it was conceivable that, enalapril and lisinopril being long-acting ACE inhibitors, there could be a greater response as plasma and tissue concentrations rise over time. Our study was planned to clarify this question.

\section{Material and Method}

Twelve outpatients ( 5 males and 7 females) aged between 44 and 66 years were selected and treated. All had mild to moderate essential hypertension (duration 2 to 4 years). Their antihypertensive therapy was stopped because of insufficient effect or side effects: the patients were without treatment for 2 to 3 weeks. No other drugs were used and no contraindications to ACE inhibitors were present. The study was approved by the ethical committee and all patients gave informed consent. No patient was withdrawn before receiving the test medications because of normalization of blood pressure (BP). The test medications were placebo, enalapril, and lisinopril, $10 \mathrm{mg} /$ day given as monotherapy once a day between 7:00 and 8:00 a.m. Treatment was given according to a randomized, doubleblind, crossover design. Each test medication was given for a double-blind period of 7 days, followed by a singleblind placebo period of 4 days before the next crossover. Fixed dose regimens are necessary for research purposes; on the other hand, they are not likely to be adequate for the long-term treatment of hypertension: therefore, the duration of the treatment with the individual test medications was limited to 7 days. Hypertension was defined by a mean diastolic BP of between 95 and $115 \mathrm{mmHg}$, this 
being the mean value of a 24-h ambulatory blood pressure monitoring (ABPM). Routine prestudy clinical laboratory tests were either normal or the abnormalities were clinically irrelevant. Blood samples and laboratory plus renin estimations were taken $24 \mathrm{~h}$ after the last dose of the 1week treatment periods and $40 \mathrm{~h}$ before the ABPM. Baseline measurements of BP were obtained from the same arm throughout using simultaneously a mercury sphygmomanometer and a Disetronic CH-Druck ${ }^{\circ}$ equipment. ${ }^{8}$ Afterward, BP and heart rate (HR) were automatically measured with the $\mathrm{CH}$-Druck equipment: two times per hour between $8: 00$ and 22:00 h (daily period) and once per hour between 22:00 and 8:00 $\mathrm{h}$ (night period). Again at the end of the ABPM, BP and HR were checked simultaneously. The mean difference between manual and $\mathrm{CH}$ Druck BP was less than $3 \mathrm{mmHg}$ (range: -2 to $+2 \mathrm{mmHg}$ for systolic BP; $0+3 \mathrm{mmHg}$ for diastolic BP). ABPM was obtained 24 to $26 \mathrm{~h}$ after the last dose and during the last 24-h period of the 1-week treatment periods. Adverse events were recorded in response to the question: "Have you had any symptoms or problems since your last visit?" All data were analyzed by means of a paired $t$-test and by calculation of the area under the curve (AUC) of the ABPM. Both methods gave identical statistical values. The presentation of the clinical data (figures) was better with the paired $t$-test analysis and therefore this method was used for presentation of the results.

\section{Results}

The portable automatic CH-Druck equipment was well accepted by the patients and functioned optimally. All patients ended the study with complete ABPM profiles.

\section{Systolic Blood Pressure}

Pretreatment values were similar: placebo $170.7 \pm 6.8$; enalapril 176.5 \pm 9.5 ; lisinopril $176 \pm 7.9 \mathrm{mmHg}$ (mean \pm SD). Placebo had no effect. As shown in Figure 1, both drugs reduced systolic BP $5.5 \mathrm{~h}$ postdosing (hollow area, $\mathrm{p}<0.05)$. The hypotensive effect was slightly faster with enalapril $(2.5 \mathrm{~h}: 165.8 \pm 9.3)$ than with lisinopril $(5.0 \mathrm{~h}$ : $165.1 \pm 14.1)$. Nonetheless the global hypotensive effect was similar for enalapril and lisinopril. The hypotensive effect was also similar at the 24th h (enalapril: $162.0 \pm 6.9$, lisinopril: $160.1 \pm 6.2$ ). The diurnal rhythm was not changed.

\section{Diastolic Blood Pressure}

The pretreatment values were similar: placebo $102.3 \pm$ 3.2; enalapril 104.8 \pm 3.8 ; lisinopril $108.8 \pm 5.4 \mathrm{mmHg}$. Placebo had no effect. As shown in Figure 2, the hypotensive effect was similar for both drugs and was significant $6 \mathrm{~h}$ postdosing: enalapril $99.1 \pm 8.5$, lisinopril $97.3 \pm 4.8$ $\mathrm{mmHg}$ (hollow area of Fig. 2, p<0.05\%). The circadian rhythm was not affected.

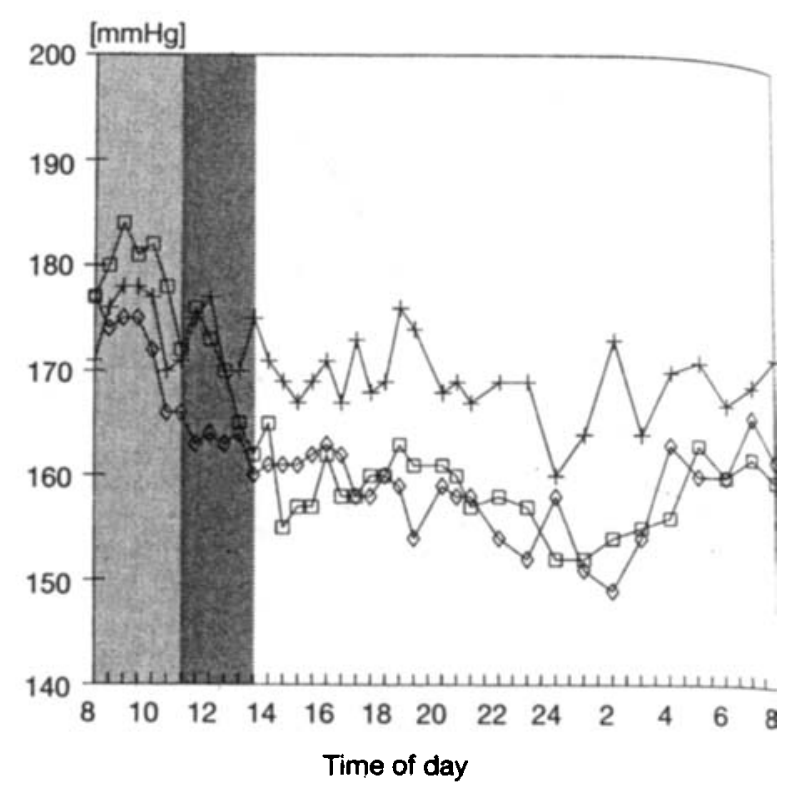

FIG. 1 Systolic blood pressure mean of 12 patients. + SBP plac bo; $\rightarrow$ SBP lisinopril; - $\rightarrow$ SBP enalapril. Light-shaded area: 1 difference between treatment; dark-shaded area: No difference b tween lisinopril and placebo, but enalapril different from placebo a lisinopril; white area: no difference between treatments but both re imens differ from placebo. $t$-test $(\mathrm{p}<5 \%)$ at each time point.

\section{Heart Rate}

Neither placebo nor the test drugs affected HR to at significant extent (Fig. 3).

\section{Renin}

As shown in Figure 4, basal values were similar for : treatment periods: placebo 3.0 \pm 0.3 ; enalapril $2.9 \pm 0$. lisinopril $2.8 \pm 0.2 \mathrm{ng} / \mathrm{ml}$. Placebo had no effect. As ev dence for the ACE inhibition, serum renin levels increase significantly $(\mathrm{p}<0.01)$ after both enalapril and lisinopr However, the effect of lisinopril was significantly great than that of enalapril: $4.7 \pm 0.3$ after enalapril; $6.6 \pm 0.4$ aft lisinopril $(\mathrm{p}<0.01)$.

\section{Side Effects}

Few side effects were observed. One patient complaine of mild nausea at Day 2 with both drugs. Another paties complained of mild headache with enalapril on Day : Drug-related effects on the laboratory results were ni detectable.

\section{Discussion}

Office blood pressures have been the primary basis fo the physician's decisions in the diagnosis and treatment $c$ hypertension. In some patients, however, the office pre: 


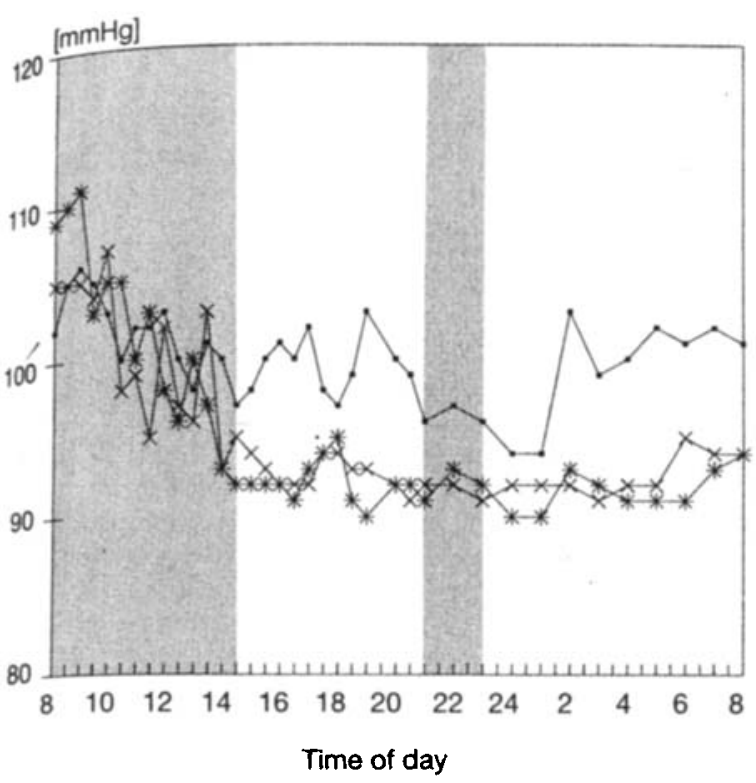

FiG. 2 Diastolic blood pressure mean of 12 patients. - DBP placebo; * DBP lisinopril; * DBP enalapril. Shaded area: no difference between treatments as well as no difference compared with placebo; white area: significant difference between placebo and both ireatments; no difference between lisinopril and enalapril. $t$-test $(\mathrm{p}<5 \%)$ at each time point.

sures may be misleading. ABPM offers complementary relevance to the value of office blood pressures and may improve treatment $t^{9,10}$ by providing information about the risk of developing clinical complications of hypertension."

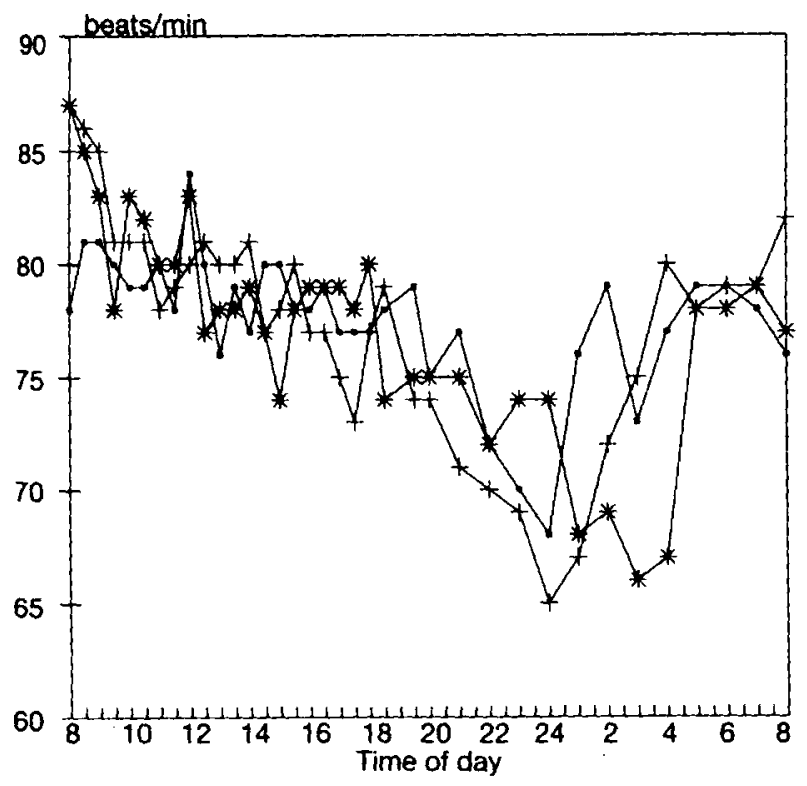

Fig. 3 Heart rate mean of 12 patients. - HR placebo; + HR lisinopril: *- HR enalapril. No difference between treatments ( $t$-test NS)

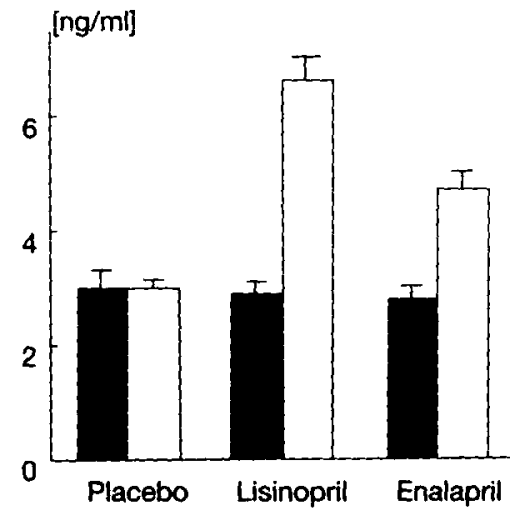

FIG. 4 Serum renin levels mean of 12 patients: $\square$ before dose; $\square 24$ h after dose. Basal values: no difference; enalapril vs. baseline: $p<0.01$; lisinopril vs. baseline: $p<0.01$; lisinopril vs. enalapril: $p<0.01$.

Our study confirms the optimal function of the CH-Druck equipment and $\mathrm{ABPM}$ was important in assessing the antihypertensive effects of the tested drugs. Our data confirm the results of the single dose study by Dews et al.:? while both drugs were equally effective and potent for the treatment of hypertension, the greater renin-inhibiting effect of lisinopril was not reflected by a greater antihypertensive effect. The antihypertensive effect of enalapril and lisinopril was similar (duration and magnitude) and persisted for $24 \mathrm{~h}$. The diurnal profile of BP and HR were not affected by treatment. On the other hand, our data do not confirm the results of the single dose study by Millar et al. ${ }^{6}$ where the antihypertensive effect of lisinopril was longer than that of enalapril. Obviously, the response of the drugs is different on repeated treatment. We used a fixed dose, and therefore our data are not sufficient for judging the effect of different doses.

In spite of a similar antihypertensive effect, the renin inhibiting effect of lisinopril was superior. Clearly, the physiologic effects of enalapril and lisinopril (and all known ACE inhibitors) are not clearly related to plasma renin alone. Indeed it has been known for some time that responses of patients with hypertension to ACE inhibitors cannot be predicted by renin profiling alone. ${ }^{13-16}$ Bradykinin, prostacyclin, and other humoral factors may play an important role in the pharmacologic effect of renin inhibitors. ${ }^{15-17}$ Renin inhibitors seem to be effective in preventing progression of ventricular dysfunction and may delay or prevent the appearance of heart failure: ${ }^{17,18}$ the full effect of these drugs, however, develops slowly and it may take more than 12 weeks to become maximal. Obviously our data from a 1 -week treatment cannot be extrapolated for the long-term treatment of patients with heart failure and, as Sir Arthur Conan Doyle said, "It is a capital mistake to theorize before one has data." However, since the greater renin-inhibiting effect of lisinopril is not accompanied by a greater antihypertensive effect, it would be interesting to compare their long-term effect in the treatment of heart failure. 


\section{References}

1. Cooper WD, Sheldon D, Kimber GR, Isitt VL, Currie WJC: Post-marketing surveillance of elanapril: Experience in 11700 hypertensive patients in general practice. $J \boldsymbol{R}$. Coll Gen Pract $37,346(1987)$

2. Wu MT, Douglas AW, Ondeyka DL: Synthesis of N-[(S)-1-carboxy-3-phenylpropyl]-L-lysyl proline (lisinopril). J Pharm Sci 74, 352 (1985)

3. Bull HG, Thomberry NA, Cordes EH: Inhibition of rabbit lung angiotensin converting enzyme by $\mathrm{N}-[(S)-1$-carboxy-3-phenylpropyl]-L-alanyl-L-proline and $\mathrm{N}-[(\mathrm{S})-1$-carboxy-3-phenylpropyl]-L-lysyl-proline. J Biol Chem 260, 2952 (1985)

4. Ulm EH, Hichens M, Gomez HJ: Enalapril maleate and a lysine analogue (MK-521) disposition in man. BrJ Pharmacol 14, 357 (1982)

5. Hodsman GP, Zabludowski JR, Zoccali C: Enalapril (MK-421) and its lysine analogue (MK-521): A comparison of acute and chronic effect on blood pressure, renin-angiotensin system and sodium excretion in normal man. Br J Clin Pharmacol 17, 233 (1984)

6. Millar JA, Derkx FH, McLean K, Reid JL: Pharmacodynamics of converting enzyme inhibition: The cardiovascular, endocrine and autonomic effects of MK-421 (enalapril) and MK-521. $\mathrm{Br}$ J Clin Pharmacol 14, 347 (1982)

7. Dews I, Wiseman WT, Al-Khawaja I, Stephens J, Vanden-Burg M: A comparison of single doses of lisinopril and enalapril in hypertension. J Human Hypertens 3, 35 (1989)

8. CH-DRUCK. Operating Manual. Disetronic Medical Systems. CH-3401 Burgdorf
9. Perloff D, Sokolow M: The representative blood pr Usefulness of office, basal, home, and ambulatory re Cardiovasc Med 3, 655 (1978)

10. Loew F, Gauthey L, Donath R, Petitot C., Herrmann F, Ja Combes B: Monitoring tensionnel chez des hypertend traités par nicardipine ou nifédipine à liberation pro Schweiz Med Wschr 120, 1887 (1990)

11. ACEline 8, 1-6 (1991)

12. Imae $\mathrm{Y}, \mathrm{Abe} \mathrm{K}$, Seino $\mathrm{M}$ : Attenuation of pressor respo norepinephrine and pitressin and potentiation of pres sponses to angiotensin II by captopril in human subjec pertension 4, 444 (1982)

13. Zusman RM: Renin and non-renin-mediated antihypen action of converting enzyme inhibitors. Kidney Int 2 (1984)

14. Moore TJ, Crantz FR, Hollenberg NK: Contribution of glandins to the antihypertensive effect and angioconvert zyme inhibition by captopril. Hypertension 2, 236 (1980

15. Cohen ML, Kurz KD: Angiotensin converting enzyme tion in tissue from spontaneously hypertensive rats afte, ment with captopril or MK421. J Pharmacol Exp Ther 2 (1982)

16. Swales JD: The renin-angiotensin system in hypertensi The Renin-Angiotensin System (Ed. Robertson JIS). Me Co., Inc., Gower Medical Publ. Ltd., 4, 4.1 (1985)

17. Nicholls MG: The renin-angiotensin system in cardiac fail, The Renin-Angiotensin System. (Ed. Robertson JIS). Me Co., Inc., Gower Medical Publ. Ltd., 5, 5.1 (1985)

18. Cleland JGF: ACE inhibitors in mild heart failure: First-I second-line therapy? Eur Heart J 11 (suppl D), 53 (1990) 